\title{
CYBER VULNERABILITY OF JAPANESE BANKING/FINANCIAL SYSTEM
}

\author{
Anna Davtyan
}

Core K.K., Meiji University, Toyo Gakuen University

This study discusses the cyber vulnerability of Japanese Banking System and possible correlation with aging and considerably, less financial technologies educated population. As for 2020 there were taking place many major events regarding financial system databases leaked and in case Dokomo NTT Docomo Inc., the nation's largest mobile phone carrier, about $¥ 28$ million has been stolen from bank accounts linked to an e-money service operated by NTT Docomo Inc. When many of victims were not aware of their accounts connection to the NTT Docomo.

As nowadays we use financial services online more frequently, it should be given more attention to customer awareness of possible cyber crimes and warn them appropriately.

Keywords: banking/financial system; cyber vulnerability; fintech literacy

\section{Introduction}

Many researchers discussed issues that can arise from low birth rate and aging population of Japan, one of those being a tech literacy, especially financial tech literacy.

From Japan's demographic pyramid, we can see that almost 30 percent of its population being elderly inhabitants, Japan is considered the "oldest" country in the world today.

In this digitalized era, especially during pandemic the digitalization took over the operation and management of each field/sector, especially financial, banking field. We do/did online shopping, paid our bills online, do/ did online transactions. Would it be safe to assume that Japan's population majority is tech friendly?

In 2019 many were already concerned with the coverage of tech literacy in Japan, especially financial technology (fintech) literacy. One of the of the topics discussed during G20 Summit in 2019 was Digital Fianacial Literacy and the importance and especially

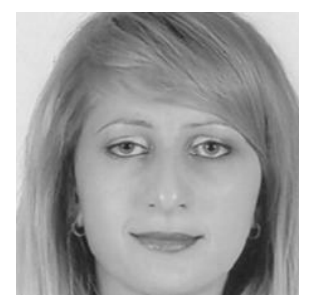

\footnotetext{
Anna Davtyan

PhD., Core K.K., Meiji University, Toyo Gakuen University

Research interests: international tourism market, tourism impact on local society, government stimulation of tourism and tourism macro-marketing

Published more than 20 researches, participated in 14 International conferences

Email:a.davtyan@coresecurity.co.jp, anna.davtyan@tyg.jp
} 


\section{CYBER VULNERABILITY OF JAPANESE}

consumer's understanding, financial sophistication, making effective use of fintech products and avoiding fraud and costly mistakes.

Mitusure Obe (2020) in the work published in Nikkei Asia talks about the aging Japan and that Elderly and Vulnerable Japanese hold half the country's 17 trillion U.S. Dollars, financial assets.

Mitsui continues by highlighting numbers: that the assets are owned by people aged 65 or older, according to research from Kohei Komamura (a gerontologist at Keio University in Tokyo). The share of 75 yo or above, is expected to increase from $50 \%$ to over $60 \%$ by 2030. The Financial Services Agency $(2020,2020$ a) predicts that $\$ 2$ trillion in personal financial assets, or over $10 \%$ of the nation's total, will be in the hands of people with dementia by 2030 (Fig. 1).

Figure 1 - Japan's Population Pyramid 10.01.2019

(Source: Population Phyramid.net)
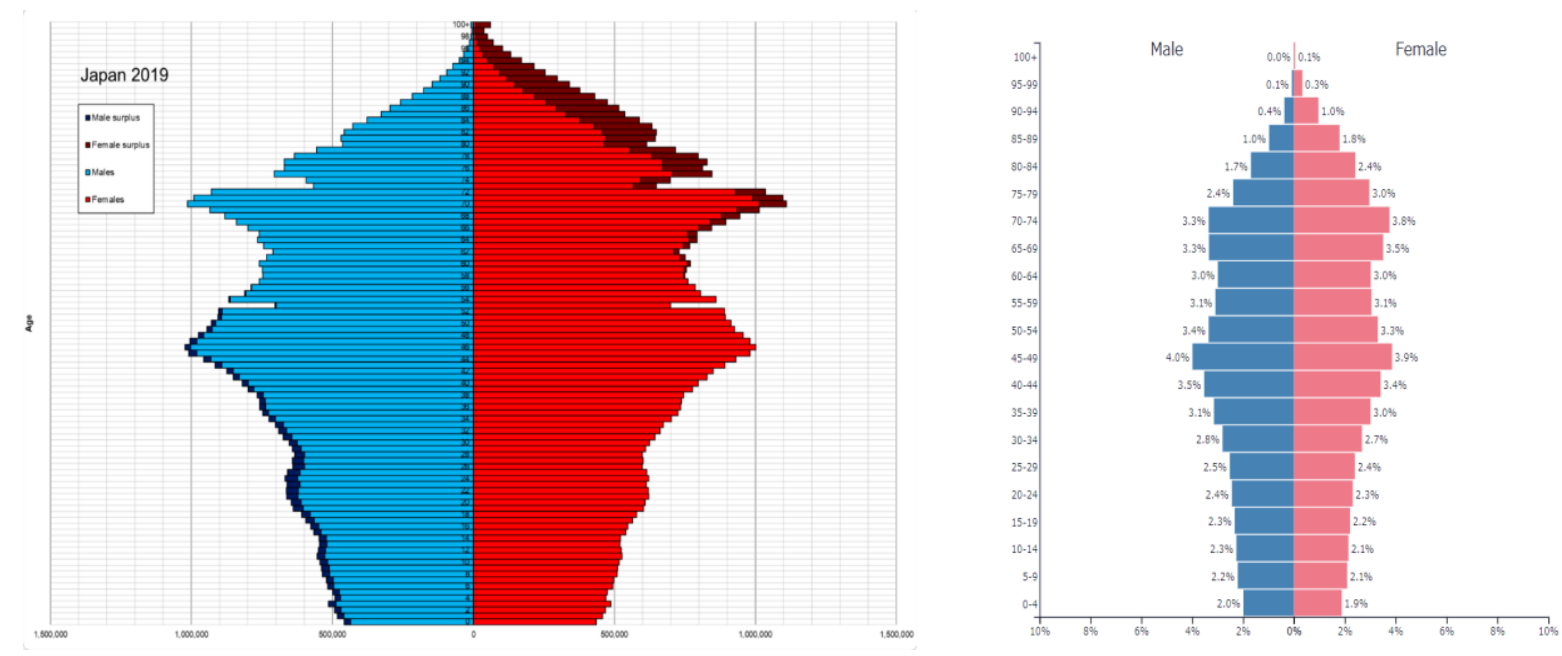

In May 2021 Statista published numbers regarding financial assets. The report states that in 2019, the total financial assets of financial institutions in Japan amounted to be almost 38.8 trillion U.S. Dollars. If we assume that there was no big of a change for assets by 2020 , 45 present of the overall Japanese financial assets are hold by the elderly citizens of Japan.

However, unfortunately giving much attention to neither digital financial literacy nor secure use of it did not take place and in September 2020, huge news broke the internet.

About $¥ 28$ million has been stolen from bank accounts linked to an e-money service operated by NTT Docomo Inc., the nation's largest mobile phone carrier, has made headlines in recent weeks, serving as a wake-up call for all concerned on the risks of e-money (Tsukumori, 2020).

Joji (2020) also had a piece on Nippon.com regarding the case with the Docomo, "Docomo Hack Reveals Vulnerabilities in Banking System".

With the purpose of seeking answers on how could it happen a cybersecurity expert Masamoto Kenzo, director of Macnica Networks was interviewed. 
Masamoto Kenzo explained the process with most easiest possible way, simple and understandable for everyone.

He mentioned that there were three possibilities:

The first is phishing-i.e. the criminals stole the information by sending the victims emails containing links to fake bank websites and tricked them into entering their names and passwords.

The second is that the attackers emailed the victims files that infected their smartphones or PCs with a virus, so that when these users used their PCs to make an online transaction, the virus stole their usernames and passwords.

The third involves a kind of fraud that is accomplished by impersonating a police officer and asking elderly victims to disclose their bankcard numbers and PINs.

These types of crimes are nothing new. According to figures from the Japanese Bankers Association, there were 863 cases of online hacking in the fourth quarter of 2019 alone, in which a total of $¥ 1.1$ billion was stolen.

Tsukumory (2020) in the work published in Japan Times talks about other Japanese Banking Cyber-attack cases:

Online broker SBI Securities Co. announced that nearly $¥ 99$ million had been stolen after six of its customers' accounts were improperly breached.

Japan Post Bank Co. also announced that $¥ 60$ million had been stolen from its customers' accounts due to unauthorized money transfers to NTT Docomo accounts and six other e-money services, including PayPay, Line Pay and prepaid debit card mijica.

The most shocking part with the NTT Docomo case was that unlike previous similar scams such as Seven Pay Co., most of the NTT Docomo case victims weren't even aware that they had NTT Docomo accounts under their names, causing the incident to catch them off guard.

In one hand specialists should find out the most possible ways that the occasion took place and try to come up with solutions for making strong uncheckable system for excluding the chances of the incident taking place again.

In other hand, why and how were created accounts on the NTT Docomo platform without the knowledge of the owners of the particular accounts???...

\section{Literature Review}

Although it was not long ago, in January 1997, the first online banking service was launched by Sumitomo Bank, and maybe a by 2006, online banking had become a mainstream (Sarreal, 2019).

In Cyber Security Trends Report (2021) published by PURPELSEC Inc., where available information regarding cyber security and its statistics in many aspects:

Social Engineering Statistics, Cryptojacking, Ransomware Statistics, etc...

Some other highlights that are important and to be taken into consideration when it comes to securing banking system and generally cybersecurity:

Cybercrime Risen Up 600\% Due To COVID-19 Pandemic.

Malware and web-based attacks are the two most costly attack types - companies spent an average of US \$2.4 million in defense.

Ransomware attacks are estimated to cost \$6 trillion annually by 2021 . 


\section{CYBER VULNERABILITY OF JAPANESE}

$50 \%$ of a surveyed 582 information security professionals do not believe their organization is prepared to repel a ransomware attack.

Luyendijk (2015) is talking about megabanks and that the megabanks have tens and sometimes hundreds of thousands of employees, operating 24/7 across six continents in activities of a widely different nature and complexity, with trillions of dollars going through their systems every day. The key term here is "systems". Today's global megabanks did not grow slowly and organically to their current size. They grew in jumps by taking over or merging with other banks and financial institutions of wildly varying sizes, spread out over the globe.

Table 1 - Few cyber attacks/events during 2021

(Source: PUPLESEC Inc, 2021)

\begin{tabular}{l} 
PayPal SMS Phishing Scheme, January 1 \\
A new SMS-based phishing scheme has been targeting PayPal in an attempt to gain \\
access to accounts. \\
American Express Leak, January 5 \\
A hacker posted data of 10,000 Mexico-based American Express card users on a forum \\
for free. \\
\hline Reserve Bank of New Zealand Data Breach, January 10 \\
The Reserve Bank of New Zealand suffered a data breach after actors illegally accessed \\
its information through one of the bank's third-party file sharing services. \\
\hline Cuba Ransomware Attacks Payment Processors, February 3 \\
Automatic Funds Transfer Services, a payment processor, suffered a ransomware attack \\
by a group called Cuba Ransomware. \\
\hline IRS Warns of Phishing Attacks, February 10 \\
Internal Revenue Service (IRS) warned US tax professionals of a phishing scam \\
attempting to steal the tax preparer's identity. \\
\hline Sequoia Capital Discloses Data Breach, February 19 \\
On February 19, 2021, Sequoia Capital informed its investors of a data breach \\
jeopardizing some of their personal and financial information. \\
\hline Wall Street Targeted In New Capital Call Fraud Scheme, March 3 \\
A cybersecurity firm reported Capital Call Investment scams as the latest threat vector \\
used to swindle exorbitant amount of money from Wall Street firms and their clients. \\
\hline FINRA Sends Scam Alert To Brokerage Industry, March 4 \\
Financial Industry Regulatory Authority (FINRA) warned member firms of an ongoing \\
phishing campaign involving emails sent by impersonators. \\
\hline FBI Attributes Loss of \$4 billion to Cybercrime, March 17 \\
FBI released its Internet Crime Report 2020 which stated that American victims reported \\
$\$ 4.2$ billion in losses as a result of cybercrime and internet fraud to the FBI last year. \\
\hline
\end{tabular}

Kumire (2020) highlights the reasons for targeting banks; cybercriminals target banks because their data is more valuable. Whereas information on a social media site may lack detail or accuracy, bank data will contain details such as addresses and dates of birth. This data has inherent value and can be used for other malicious activity such as ID fraud, which makes the consequences of attacks more devastating. 
Funding for IT systems was often inadequate - if only because such long-term investments come at the expense of short-term profits. In many banks, different parts of the business have different systems, and many banks have different systems in different countries. These have evolved over the years, step by step, one added to another. IT specialists talked about "patches", to integrate new products into these myriad systems, and about "workarounds", improvised solutions when an activity or product cannot be properly processed. There are systems used to run all these systems, and systems to run those, and so on (Luyendijk, 2015).

Although it could be the information is from 6 years ago, but the fact that the number of cyber attacks on banking system keeps rising it can be concluded that some part as a reason still be inadequate funding of IT system.

Carnegie Endowment (GE) offers decision makers global, independent, and strategic insight and innovative ideas that advance international peace.

On the website of GE, under the section "Timeline of Cyber Incidents Involving Financial Institutions", can be found a timeline chronicles 200 cyber incidents targeting financial institutions since 2007, and can be filtered by country, region, year, attribution, incident type, and actor type.

The urgency in addressing cybersecurity is boosted by a rise in incidents. According to FCA reports, data breaches at financial services companies have increased by over 1,000 percent between 2017 and 2018. Over a quarter of global malware attacks targeted financial services providers - the highest rates for any industry. Recently, Travelex garnered the wrong kind of headlines after a ransomware attack forced them to shut down their websites in 30 countries.

Parthasarathy (2021) in the "How banks can address rising cyber security threats to protect customers" article writes that the first step in the cyber security journey is to create a comprehensive policy governance framework, experts at the workshop said. The framework must not be riddled with high-level objective statements, but instead lay out the policy direction in clear, concise and granular details.

Also highlights that; cyber criminals are in for the long haul and our response to the threat they pose must be on similar lines. Financial institutions must develop people, processes and technology to assess risk and build controls that are commensurate with the organization's risk appetite.

The World Economic Forum, which engages the foremost political, business, cultural and other leaders of society to shape global, regional and industry agendas, published top cybersecurity challenges of 2021(Pipikate et.al.,2021).

Top Cybersecurity Challenges are:

- More complex cybersecurity challenges

- Fragmented and complex regulations

- Dependence on other parties

- Lack of cybersecurity expertise

- Difficulty tracking cyber criminals

- Education plays role in each and every sector, a combination of customers that are well informed about the risk of cyber attacks and well trained, educated cybersecurity specialists could lower risks, number of cyber attacks.

Financial Guerantee Insurance Brokers Inc. (FGIB) published results of a survey that reveals that consumers want cyber education from their banks. 


\section{CYBER VULNERABILITY OF JAPANESE}

A bank technology firm CSI conducted a survey asking banking customers what they wanted from their banks when it comes to financial data breaches. The results highlighted a need for awareness and education around such issues, painting a picture of how important it is to stay informed.

CSI's survey results show that nearly three-quarters of consumers (about 74 percent) would likely participate in a cybersecurity awareness or education program from their own financial institution if they offered it. The survey, conducted through The Harris Poll on behalf of CSI, also found that an overwhelming majority of banking customers have concerns about the overall safety of their personal data online (about 92 percent) (FGIB, 2019).

Education has always been and will remain critical in tackling cybersecurity issues. Historically, the issue of defending against attacks has been viewed as a job only for the IT departments, but firms need to adopt a holistic approach to security, and introduce basic hygiene measures for all those involved in banking processes including the consumers and employees (Kumire, 2020).

\section{Suggestions}

By taking to account the cyber-attacks that took place just last year and the fact that majority of financial assets are in the hands of citizens of the age of 65 and above, cab be concluded that Japanese banks, financial institutions are at its highest risks of experiencing data breaches, being cyber vulnerable.

Official institutions, Japanese Government should give much attention to fintech literacy, organizing seminars, webinars, events, co-operate with the local government and locally operating cybersecurity companies.

It would be best move from government side to unify, make simplified application for financial operations and provide the guidance of use to the population generally and especially to the citizens towards 60s. Should make a mandatory the cyber audits few times in year, check on cyber vulnerabilities of financial institutions.

\section{References}

FGIB. (2019). Recent Survey Reveals That Customers Want Cyber Education from Their Banks. Available at: https://www.fgib.com/recent-survey-reveals-that-customers-want-cybereducation-from-their-banks/

Financial Services Agency. (2020). Financial Sector Cybersecurity Report. Available at: https://www.fsa.go.jp/en/news/2020/20201127/cybersecurity.pdf

Financial Services Agency. (2020a). Publication of reports on IT and cybersecurity initiatives. Available at: https://www.fsa.go.jp/en/news/2020/20201127.html

Joji, M. (2020). How to steal $¥ 28$ million: Lessons learned from the Docomo swindle. Japan Times. Available at: https://www.nippon.com/en/in-depth/d00628/

Kumire, J. (2020). How are banks dealing with a rise in cyber attacks? Financial Services. Available at: https://content.11fs.com/article/how-are-banks-dealing-with-a-rise-in-cyber-attacks

Luyendijk, J. (2015). Cyber attacks could be bigger threat to our banking system than bad debts. The Guardian. Available at:https://www.theguardian.com/sustainable-business/2015/oct/24/cyberattacks-could-be-bigger-threat-to-our-banking-system-than-bad-debts 
Obe, M. (2020). Aging Japan: Banks turn to technology to tackle looming demographic crisis. Nikkei Asia. Available at: https://asia.nikkei.com/Spotlight/The-Big-Story/Aging-Japan-Banks-turnto-technology-to-tackle-looming-demographic-crisis

Parthasarathy, P. (2021). How banks can address rising cyber security threats to protect customers. Available at: https://www.thenationalnews.com/business/ money/2021/09/15/how-banks-canaddress-rising-cyber-security-threats-to-protect-customers/

Pipikaite, A., Barrachin, M. \& Crawford, S. (2021). These are the top cybersecurity challenges of 2021. World Economic Forum. Available at: https://www.weforum.org/agenda/2021/01/topcybersecurity-challenges-of-2021/

PUPLESEC Inc. (2021). 2021 Cyber Security Statistics, The Ultimate List Of Stats, Data \& Trends. PUPLESEC Inc. Available at: https://purplesec.us/resources/cyber-security-statistics/

Sarreal, R. (2019). History of Online Banking: How Internet Banking Went Mainstream. GO Banking Rates. Available at: https://www.gobankingrates.com/banking/banks/history-online-banking/

Tsukumori, O. (2020). How to steal $¥ 28$ million: Lessons learned from the Docomo swindle. Japan Times. Available at: https://www.japantimes.co.jp/news/2020/09/25/business/lessons-from-nttdocomo-swindle/

Paper submitted

Paper accepted for publishing

Paper published online
16 September 2021

21 October 2021

31 January 2022 